\title{
Anesthetic Management for a Patient of Gorham's Syndrome: The Vanishing Bone Disease
}

\author{
Aiji Sato (Boku)ㄹ, Eisuke Kako², Megumi Harima², Jun Harada1, Kazuya Sobue ${ }^{2}$ \\ ${ }^{1}$ Department of Anesthesiology, Aichi Gakuin University School of Dentistry, Nagoya, Japan \\ ${ }^{2}$ Department of Anesthesiology and Intensive Care Medicine, Nagoya City University Graduate School of Medical Sciences, \\ Nagoya, Japan \\ Email: bokuaiji@dpc.agu.ac.jp
}

How to cite this paper: Sato (Boku), A., Kako, E., Harima, M., Harada, J. and Sobue, K. (2017) Anesthetic Management for a Patient of Gorham's Syndrome: The Vanishing Bone Disease. Open Journal of Anesthesiology, 7, 147-151.

https://doi.org/10.4236/ojanes.2017.76015

Received: May 19, 2017

Accepted: June 16, 2017

Published: June 19, 2017

Copyright $\odot 2017$ by authors and Scientific Research Publishing Inc. This work is licensed under the Creative Commons Attribution International License (CC BY 4.0).

http://creativecommons.org/licenses/by/4.0/

\begin{abstract}
Gorham-Stout (GS) syndrome or the vanishing bone disease is a very rare chronic disease characterized by the destruction of the osseous matrix and proliferation of vascular structures. Review of the general anesthesia showed only a few cases till date. We report general anesthesia for tooth extraction in a 21-year-old male patient with Gorham-Stout syndrome. In this case, the most concerning issue was limited mouth opening due to mandible osteolysis and difficult intubation was anticipated. To anticipate difficult airway management, it is very important to consider the preoperative airway assessment including the cervical spine screening. In this case, the McGrath video laryngoscope prevented the anticipated difficult intubation due to the limited mouth opening due to mandible osteolysis.
\end{abstract}

\section{Keywords}

Gorham's Syndrome, Massive Osteolysis, General Anesthesia, Airway Evaluation

\section{Introduction}

Gorham-Stout (GS) syndrome or the vanishing bone disease is a very rare chronic disease characterized by the destruction of the osseous matrix and proliferation of vascular structures. Its etiology hasn't been clarified. The syndrome affects one or multiple bones of the patients, including the skull, the upper and lower extremities, the spine and pelvis. The clinical presentation of a patient suffering from vanishing bone disease includes, pain, functional impairment and swelling of the affected region [1]. Although 175 cases of GS syndrome have been reported in the literature till date, we could obtain only a few cases with GS 
syndrome which described that special attention should be given to airway management and anticipation of postoperative pulmonary complication [2] [3] [4] [5] [6]. We describe the anesthetic management of a 21-year-old male with GS syndrome, who was scheduled for tooth extraction under general anesthesia. In this case, the most concerning issue was limited mouth opening due to mandible osteolysis and difficult intubation was anticipated.

\section{Case Report}

We obtained the patient's consent for the case report to be published.

A 21-year-old male patient, whose weight and height were $58 \mathrm{~kg}$ and $174 \mathrm{~cm}$, respectively, presented with pain in his right mandible. In 2013, he developed orthostatic headache, and a CT image revealed osteolysis in the petrous bone near the right carotid artery. MRI revealed a high T2 image, considered to indicate cerebrospinal fluid (CSF), between the cervical muscle and bone. The patient was hospitalized because of CSF hypovolemia with CSF transudation from the right temporal bone. Since then, he has been observed without any special treatment.

During this time, he was scheduled for tooth extraction owing to pericoronitis of a wisdom tooth and bone extraction for precise diagnosis under general anesthesia. Routine laboratory tests, electrocardiogram (ECG), spirometry, and chest X-ray were all normal. Cervical mobility was within the normal limit. Limited mouth opening due to mandible osteolysis was observed and the inter-incisor distance was only $2 \mathrm{~cm}$. A preoperative CT image of the lower right mandible revealed an increment in osteolysis (Figure 1, Figure 2). Panoramic $\mathrm{X}$-ray photograph also showed osteolytic change of the right mandible (Figure 3 ). No premedication was administered prior to the general anesthesia. Anesthesia was induced by propofol $(150 \mathrm{mg})$, remifentanil $(0.25 \mu \mathrm{g} / \mathrm{kg} / \mathrm{min})$, and fentanyl $(100 \mu \mathrm{g})$. Nasotracheal intubation was facilitated by rocuronium bromide (40 mg). Due to mandible osteolysis and limited mouth opening, intubation was expected to be difficult; therefore, the McGrath video laryngoscope with BURP was used to perform the nasotracheal intubation, which was achieved in the first try. Anesthesia was maintained by continuous infusion of propofol at $3 \mu \mathrm{g} / \mathrm{ml}$

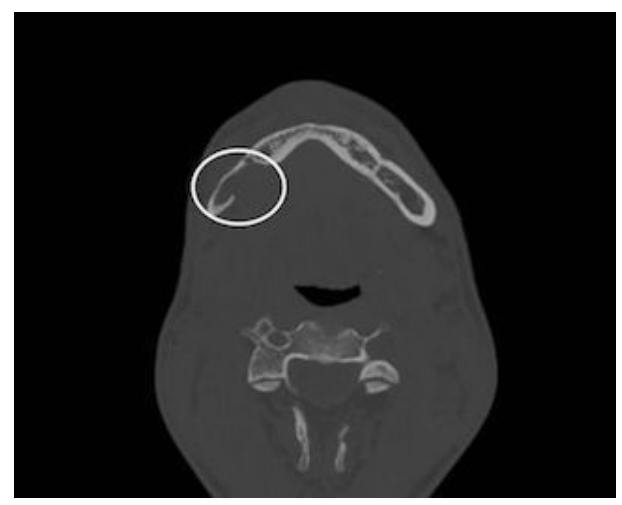

Figure 1. A preoperative CT image of the lower mandible. White ring shows an increment osteolysis in lingual side mandible. 


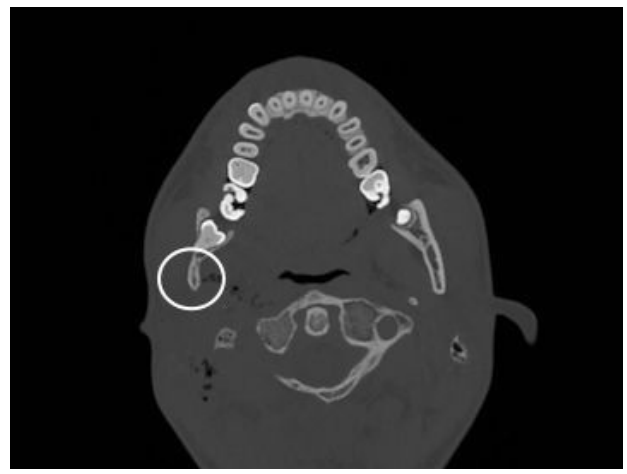

Figure 2. A preoperative CT image of the lower mandible. White ring shows an increment osteolysis in ramus of mandible.

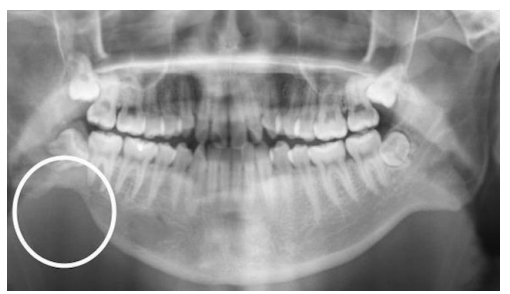

Figure 3. A preoperative Panoramic X-ray photograph. White ring shows an increment osteolysis in the right mandible.

and remifentanil at $0.1-0.25 \mu \mathrm{g} / \mathrm{kg} / \mathrm{min}$ with $40 \%$ oxygen in air. Intraoperative monitoring included ECG, non-invasive BP, capnometry, pulse oximetry, temperature, urine output, train of four using TOF Watch and gas analyzer. Vitals were stable throughout the surgery. Pain management involved administration of IV acetaminophen $1000 \mathrm{mg}$ in the operation room before the end of the surgery. At the end of the surgery, we administered sugammadex $100 \mathrm{mg}$ and extubated after completely awaking. Then, the patient was shifted to the post-anesthesia care unit (PACU) and administered oxygen $3 \mathrm{l} / \mathrm{min}$ using a face mask. The patient was observed for $1 \mathrm{~h}$ in the PACU after extubation and then shifted to his room without any complication.

\section{Discussion}

The etiology of the massive osteolysis that occurs in GS syndrome is not well known. This disease occurs most commonly in adolescence and in the second and third decades, although the age range of those affected is between 1.5 and 72 years [7] [8]. There is no incidence of sexual or racial predominance. GS syndrome is diagnosed based on clinical examination, radiological imaging, and biopsy. In this case, the patient was accurately diagnosed using the extracted bone (Figure 4). There are some treatments for GS syndrome, such as radiation therapy [9], anti-osteoclastic medication, and alpha-2b interferon [10]. Surgical treatment options include resection of the lesion, instrumentation using bone grafts, and prostheses. In this case, the patient has received sirolimus therapy which is used for the treatment of lymphangioleiomyomatosis.

As previously described, only a few case reports have described the use of 


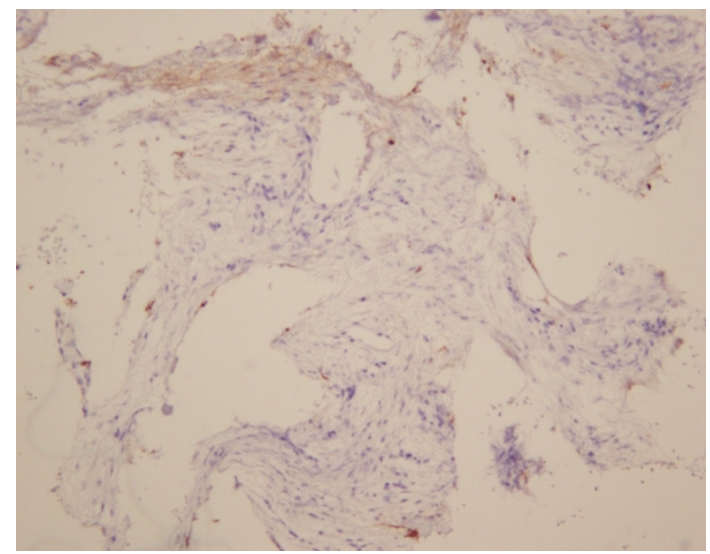

Figure 4. Histopathological image of Mandibular bone (Immunostaining). Accumulation of vasculature which is $\mathrm{D} 2-40$ positive can be seen.

general anesthesia for GS syndrome. To anticipate the intubation problem, cervical spine screening should be included in the preoperative evaluation because spinal involvement was noted in 42 of the 175 reported cases with 15 primary and secondary lesions. Furthermore, a complete respiratory assessment should be performed, including chest X-rays, oxygen saturation in air, arterial blood gases, and spirometry. If there is a restrictive lung disease, ventilation using low tidal volume and high respiratory rate should be considered. Fortunately, in this case, there were no concerns about cervical spine screening and respiratory assessment, although we did not perform an analysis of arterial blood gases.

Among the patients with primary osteolysis such as GS syndrome, difficult intubation was encountered in $64 \%$ and postoperative ventilation was required in $27 \%$. Therefore, preoperative assessment of a patient with primary osteolysis should include an appropriate strategy for managing a potentially difficult airway [11]. As we described, the most concerning issue was limited mouth opening due to mandible osteolysis and we anticipated difficult intubation. Especially in our case, a part of the masseter muscle and the inner pterygoid muscle, which are mouth opening/closing muscle, were replaced with lymphatic tissue and which was thought to be the cause of limited mouth opening. We initially planned to perform fiber-optic intubation while the patient was awake as well as under sedation. But it is said that required awake fiber-optic intubations as the disease process caused progressive distortion of airway structures in the patient with primary osteolysis [11]. Therefore, nasotracheal intubation was successfully performed using the McGrath video laryngoscope with BURP under general anesthesia.

\section{Conclusion}

We reported the anesthetic management of a patient with GS syndrome. To anticipate difficult airway management, it is very important to consider the preoperative airway assessment including the cervical spine screening. In this case, the McGrath video laryngoscope prevented the anticipated difficult intubation due to the limited mouth opening due to mandible osteolysis. 


\section{Conflict of Interest}

The authors declare no conflicts of interest.

\section{References}

[1] Vasileios, S.N., Dimitrios, C., Demitrios, K. and Efstathopoulos, N. (2014) Vanishing Bone Disease (Gorham-Stout Syndrome): A Review of Rare Entity. World Journal of Orthopedics, 18, 694-698.

[2] Mangar, D., Murtha, P.A., Aquilina, T.C. and Connell, G.R. (1994) Anesthesia for a Patient with Gorham's Syndrome: "Disappearing Bone Disease". Anesthesiology, 80, 466-468. https://doi.org/10.1097/00000542-199402000-00027

[3] Szabo, C. and Habre, W. (2000) Gorham Syndrome: Anaesthetic Management. Anaesthesia, 55, 157-159. https://doi.org/10.1046/j.1365-2044.2000.055002157.x

[4] Yildiz, T.S., Kus, A., Solak, M. and Toker, K. (2009) The Gorham-Stout Syndrome: One Lung Ventilation with a Bronchial Blocker. A Case of Gorham's Disease with Chylothorax. Pediatric Anesthesia, 19, 190-191. https://doi.org/10.1111/j.1460-9592.2008.02832.x

[5] Gambling, D.R., Catanzarite, V., Fisher, J. and Harmas, L. (2011) Anesthetic Management of a Pregnant Woman with Gorham-Stout Disease. International Journal of Obstetric Anesthesia, 20, 85-88. https://doi.org/10.1016/j.ijoa.2010.09.007

[6] Calderón, L.E., Maggi, G., Guasch, E. and Gilsanz, F. (2012) Anaesthetic Implications of Gorham Syndrome. Revista Española de Anestesiología y Reanimación, 59, 109-110. https://doi.org/10.1016/j.redar.2012.02.024

[7] Frederiksen, N.L., Wesley, R.K., Sciubba, J.J. and Helfric, J. (1983) Massive Osteolysis of the Maxillofacial Skelton: A Clinical, Radiologic, Histologic, and Ultrasrucural Study. Oral Surgery, Oral Medicine, Oral Pathology, 55, 470-480.

[8] Fisber, K.L. and Pogrel, M.A. (1990) Gorham's Syndrome (Massive Osteolysis): A Case Report. Journal of Oral and Maxillofacial Surgery, 48, 1222-1225. https://doi.org/10.1016/0278-2391(90)90543-B

[9] Hanly, J.G., Walsh, N.M. and Bresnihan, B. (1985) Massive Osteolysis in the Hand and Response to Radiotherapy. The Journal of Rheumatology, 12, 580-582.

[10] Hagberg, H., Lamberg, K. and Astrom, G. (1997) Alpha-2b Interferon and Oral Clodronate for Gorham's Disease. Lancet, 350, 1822-1823. https://doi.org/10.1016/S0140-6736(05)63639-2

[11] Herd, R.S., Sprung, J. and Weingarten, T.N. (2015) Primary Osteolysis Syndromes: Beware of Difficult Airway. Pediatric Anesthesia, 25, 727-737. https://doi.org/10.1111/pan.12643 
Submit or recommend next manuscript to SCIRP and we will provide best service for you:

Accepting pre-submission inquiries through Email, Facebook, LinkedIn, Twitter, etc. A wide selection of journals (inclusive of 9 subjects, more than 200 journals)

Providing 24-hour high-quality service

User-friendly online submission system

Fair and swift peer-review system

Efficient typesetting and proofreading procedure

Display of the result of downloads and visits, as well as the number of cited articles Maximum dissemination of your research work

Submit your manuscript at: http://papersubmission.scirp.org/

Or contact ojanes@scirp.org 